\title{
ESPAÇO E MORTE NAS REPRESENTAÇÕES SOCIAIS DAS TRAVESTIS E TRANSEXUAIS FEMININAS
}

SPACE AND DEATH IN SOCIAL REPRESENTATIONS OF TRAVESTIS AND FEMALE TRANSSEXUALS

\author{
Vinícius Cabral ${ }^{1}$, Joseli Maria Silva ${ }^{1}$ \\ ${ }^{1}$ Universidade Estadual de Ponta Grossa (UEPG), Ponta Grossa, PR, Brasil \\ Correspondência para: Joseli Maria Silva (joseli.genero@gmail.com) \\ doi: 10.12957/geouerj.2016.19286 \\ Recebido em: 21 out. 2015 | Aceito em: 11 fev. 2016
}

\section{RESUMO}

A pesquisa compreende como os espaços de morte são representados pelas travestis e transexuais femininas. Para a construção do presente artigo foram realizadas oito entrevistas em profundidade com travestis e transexuais femininas que, naquele momento, residiam no estado do Paraná. A estimulação do discurso sobre espaço e morte foi realizada por meio da utilização de notícias sobre este tema, veiculadas em jornais on line. As entrevistas foram analisadas por meio de análise de conteúdo que possibilitou reconhecer os significados instituidores de representações sociais criadas por travestis e transexuais sobre a relação entre espaço e morte. As representações sociais instituídas pelo grupo trazem a ideia de violência crescente, culpabilizando o próprio grupo pela sua condição de marginalidade e, além disso, traz o território da prostituição como possibilidade de vida e simultaneamente de risco de morte.

Palavras-chave: Espaço; Morte; Representações Sociais; Travestis; Transexuais Femininas.

\begin{abstract}
The research comprises how the spaces of death are represented by travestis and female transsexuals. For the construction of this paper were conducted eight interviews with travestis and female transsexuals who ware living at that time in Paraná- Brazil. The stimulation of discourse about space and death was accomplished through the use of news on this topic, conveyed in newspapers on line. The interviews were analyzed using content analysis which was enable to build and recognize the meanings of social representations created by the group on the relationship between space and death. Social representations established by the group bring the idea of increasing violence, blaming the group for its own marginality condition and moreover, brings the territory of prostitution as a possibility for life and simultaneously as well as risk of death.
\end{abstract}

Keywords: DEM, geoprocessing, environmental legislation, permanent preservation area, environmental protection area.

\section{INTRODUÇÃO}

O artigo responde à seguinte questão central "Como os espaços de morte são representados pelas travestis e transexuais femininas?" A busca de produção de inteligibilidade relacionada ao fenômeno da morte se estabeleceu ao longo da trajetória do Grupo de Estudos Territoriais (GETE) que vem estudando várias relações entre gênero, sexualidades e espaço, como é o caso de Ornat (2008), Silva (2009) e Cabral, Silva e Ornat (2013). Estas pesquisas evidenciam que a vida das pessoas que ousam 
transgredir às normas hegemônicas de gênero são alvos de constante violência e são vulneráveis ao risco de morte violenta.

O Paraná apresentou-se como um interessante recorte espacial, na medida em que ele figura como o estado de maior número de ocorrências de violência e morte do sul do Brasil entre 2008 e 2013, segundo os Relatórios Anuais do Grupo Gay da Bahia. Nesse período, do total de 78 mortes de travestis e transexuais ocorridas na região sul do Brasil, o Paraná representa $64,1 \%$ dos casos, Santa Catarina 12,82\% e o Rio Grande do Sul 23,08\% (MOTT e CERQUEIRA, 2003).

Embora as oito pessoas entrevistadas estivessem residindo no Paraná no momento da entrevista, é importante destacar que o fato do grupo realizar constantes deslocamentos entre cidades para exercer a atividade de prostituição, suas representações sociais são constituídas de uma multiplicidade de espacialidades, fruto das experiências acumuladas ao longo da vida. A amostra de sujeitos atingiu a saturação de tendências discursivas conforme aponta Sá (1998).

As pessoas entrevistadas foram estimuladas pela leitura e visualização de imagens de seis notícias veiculadas por jornais on-line que divulgavam a morte de pessoas trans. Logo após a leitura das notícias elas foram entrevistadas por meio de um roteiro de entrevista dirigida que tinha por base os seguintes eixos investigativos: 1-As experiências de morte de pessoas de seu grupo social; 2-As experiências de violência sofridas e as expectativas de sua própria morte. O conteúdo dos discursos foram analisados a partir da metodologia de análise de conteúdo de Bardin (1977) que permitiu a construção de uma rede semântica de significados que representam a relação entre espaço e morte para o grupo investigado.

O artigo está estruturado em três partes. Na primeira parte são evidenciadas a relação entre representações sociais, espaço e morte para sujeitos dissidentes na normatividade heterossexual. $\mathrm{Na}$ segunda parte do texto foram analisadas as experiências crescentes de violência sofridas pelo grupo e na terceira parte, são evidenciadas suas expectativas de futuro mediadas pelo cotidiano de exclusão e violência. 


\section{Espaço, Morte e Representações de Travestis e Transexuais Femininas}

Várias são as polêmicas de tentativa de definição dos limites entre o que seria a travesti ${ }^{1}$ e a transexual feminina. Inúmeras discussões apontam similaridades e oposições entre ambos os grupos. Travestis e transexuais são pessoas que foram designadas como sendo do sexo masculino quando nasceram, entretanto, possuem identidade de gênero feminina e vivem suas vidas a partir de feminilidades específicas ${ }^{2}$. Tanto as travestis como as transexuais realizam transformações corporais para atingir a feminilidade desejada e assim, realizam uma difícil transgressão da norma de gênero imposta pela sociedade que entende haver uma linearidade entre o sexo, o gênero e o desejo (BUTLER, 2003 e 2006a).

Nesta pesquisa foi adotada a postura de aceitar a autoidentificação das pessoas entrevistadas, em vez de tentar realizar categorizações (DOAN, 2010). Tanto as travestis como as transexuais femininas realizam uma contundente transgressão da heteronormatividade ${ }^{3}$ ao vivenciarem sua feminilidade a partir de um corpo designado como masculino ao nascer (BUTLER, 2006a). Elas pagam o preço da transgressão de ultrapassar os limites impostos socialmente com a exclusão, violência e morte. É esta semelhança que fez com que ambos os grupos, travestis e transexuais femininas, sejam tratados por esta pesquisa como fazendo parte de um mesmo conjunto de pessoas vulnerável à morte violenta, como apontam Silva (2013) e Ornat (2013).

O fato de a nossa sociedade estabelecer o padrão hegemônico heteronormativo como sendo expressão da normalidade, todas as pessoas que não se enquadram nas regras estabelecidas são consideradas fora da ordem e anormais. Segundo Butler (2003) o gênero não é algo natural e essencializado, ligado

\footnotetext{
${ }^{1}$ Utilizamos 'a travesti' no feminino a fim de respeitar a identidade de gênero das pessoas entrevistadas, apesar de a língua portuguesa considerar este termo como sendo masculino.

${ }^{2}$ A discussão dos limites e categorias que as pessoas trans podem ser enquadradas é bastante polêmica, conforme aponta Stryker (2006). Em nossa pesquisa algumas travestis, quando assim se denominavam, justificavam esta identificação pelo fato de que, apesar de se sentir feminina, não tinha aversão à genitália masculina, como ocorre entre as transexuais. Contudo, nem todas que se identificavam como transexuais afirmavam tal aversão.

${ }^{3} \mathrm{O}$ modelo normativo que compreende a estrutura binária dos gêneros, servindo para manter o estabelecimento da ordem heterossexual, é proposto pela autora como 'heteronormatividade'. A heteronormatividade se efetiva pelas instituições, pelas estruturas e modelos de pensamento e comportamento que colocam a heterossexualidade como o padrão natural das relações humanas e serve para desqualificar aquelas que não seguem o padrão hegemônico.
} 
diretamente à genitália do corpo sexuado. A forma como os gêneros são concebidos a partir de realidades corporais materiais é dependente da cultura. O gênero se faz na ação e 'estilização repetida do corpo, um conjunto de atos repetidos no interior de uma estrutura reguladora altamente rígida, a qual se cristaliza no tempo para produzir a aparência de uma substância, de uma classe natural de ser' (BUTLER, 2003, p. 59).

Todos aqueles que escapam ao padrão bipolar entre o masculino/macho e o feminino/fêmea são considerados seres abjetos. Os seres abjetos são pessoas desconsideradas de sua humanidade pela sociedade que se julga no direito de determinar a ordem estabelecida. Travestis e transexuais são vidas que não importam socialmente, segundo Butler (2006b) e, nesse sentido, o espaço por elas vivenciado é também um espaço negligenciado social e cientificamente.

A relação entre sexualidade e espaço analisada por Valentine (1993) evidencia que o espaço se compõe da ordem hegemônica heteronormativa, assim como de suas transgressões, evidenciando o caráter político e móvel do espaço. Muitas vezes, a ordem impõe a eliminação dos transgressores e, outras, a ordem é desafiada e modificada. A força heteronormativa que compõem a sociedade brasileira ainda gera muitas punições para travestis e transexuais femininas como visto em Silva e Ornat (2010).

As travestis e transexuais femininas, a partir de sua não linearidade entre sexo e gênero, possuem vivências espaciais que são próprias de suas identificações de gênero e sexualidades, assim como propõe Duncan (1990). O autor argumenta que o espaço não tem uma interpretação universal, mas é dependente da experiência de diferentes grupos sociais. Para ele o espaço urbano é um

\footnotetext{
quadro social da inteligibilidade dentro do qual todas as práticas são comunicadas, negociada, ou contestada. Estes discursos permitem tanto recursos bem como restrições ou limites dentro dos quais certas maneiras de pensar e de agir parece natural e além do qual a maioria aprenda a pensar que o discurso não pode ser facilmente desviado. (DUNCAN, 1990, p.16) ${ }^{4}$
}

\footnotetext{
${ }^{4}$ Tradução livre: [...] the social framework of intelligibility within which all practices are communicated, negotiated, or challenged. These discourses are both enabling resources as well as constraints or limits within which certain ways of thinking and acting seem natural and beyond which most who have learned to think within the discourse can not easily stray
} 
As travestis e transexuais femininas experienciam a cidade de uma forma específica, marcada pela transgressão da ordem de gênero e é a partir dessa posição que elas criam suas interpretações espaciais que são constituídas por representações, no sentido adotado por Moscovici (2003). As travestis e transexuais constituem explicações e teorias em torno de elementos que compõem sua vida, suas relações familiares, sociais e espaciais.

Uma das representações sociais que o espaço evoca para travestis e transexuais é apontada por Silva (2013) a partir da ideia de interdição espacial. Para ela

\footnotetext{
o espaço interdito é concebido como o efeito da ordem discursiva espacial em que práticas regulatórias são desempenhadas por aqueles que se julgam dentro da ordem e possuem o poder de exercê-la bem como o de estabelecer as formas com que determinados sujeitos devem ser excluídos. (SILVA, 2013, p.158-159)
}

São várias as espacialidades urbanas interditadas à vivência de travestis e transexuais femininas como escolas, hospitais, penitenciárias, delegacias de polícia, igrejas, o exército, clubes e danceterias. Interditadas em seus direitos espaciais, elas constituem outras espacialidades que lhes garanta 0 mínimo para sua existência, como é o caso dos territórios paradoxais da prostituição estudados por Ornat (2013).

O autor conecta a interdição à prostituição e analisa as relações de poder que as travestis e transexuais que exercem a atividade comercial sexual conseguem desenvolver para sobreviver e conquistar poder nesta espacialidade. As complexas relações estabelecidas nos territórios de prostituição intensificam, muitas vezes, sua vulnerabilidade à violência que em vários casos leva à morte.

As vivências espaciais do grupo entrevistado trazem a morte como tema presente no cotidiano. Apesar de a morte ser algo comum a todo ser humano, é um fenômeno que se manifesta de maneira distinta para os diferentes grupos sociais. A morte segundo Ariés (1975) deve ser interpretada em um determinado tempo e espaço. Tempo e espaço não são universais e assim, cada grupo pode ter 
interpretações específicas sobre o fenômeno da morte, dependendo da vulnerabilidade do grupo à violência. Butler (2006b, p. 46) argumenta que

\footnotetext{
las mujeres y las minorías sexuales, están, como comunidad, sujetas a la violencia, expostas a su posibilidad o a su realización. Esto significa que em parte cada uno de nosotros se constituye políticamente em virtud de la vulnerabilidad social de nuestros cuerpos - como lugar de deseo y de vulnerabilidad física, como lugar público de afirmación y de exposión - La pérdida y la vulnerabilidad parecen ser la consecuencia de nuestros cuerpos socialmente constituídos, sujetos a outros, ameazados por la pérdida, expuestos a outros y susceptibles de violencia a causa de esta exposición. (BUTLER, 2006b, p. 46)
}

A violência e a morte de travestis e transexuais femininas possui uma dinâmica espacial a ser compreendida do ponto de vista das pessoas que sofrem com sua posição de vulnerabilidade, sendo esse o foco das seções seguintes.

\section{A Morte de Travestis e Transexuais Femininas: o ponto final da trajetória de preconceito, discriminação e violência em suas experiências espaciais concretas}

As representações sobre os espaços que as travestis e transexuais femininas constituem estão estreitamente associadas com as suas experiências urbanas e de compartilhamento de identidades do grupo social. Nesse sentido, as experiências de interdição e o cotidiano associado à violência e ao risco de morte são elementos que marcam suas representações do espaço.

James Duncan (1990) discute sobre as diferentes possibilidades de compreensão do espaço a partir de experiências de diferentes grupos. O espaço urbano, segundo ele, não é lido e interpretado da mesma forma por todas as pessoas, as interpretações estão estreitamente ligadas aos sujeitos. Para o autor, o espaço da cidade é um sistema social que é comunicado, reproduzido, experienciado e explorado pelos diversos grupos sociais. 
No entanto, cada grupo social produz discursos próprios a partir de si e de seu grupo de pertencimento.

É neste sentido que o grupo de travestis/transexuais femininas entrevistadas possui especificidades que estão ligadas a sua trajetória de vida, constituindo uma interpretação própria.

O discurso das pessoas entrevistadas ${ }^{5}$ traz com clareza que as notícias de morte de pessoas com as quais elas possuem identificação, bem como de amigas com as quais elas partilharam a vida no grupo de travestis e transexuais, institui representações sociais de uma imagem negativa que a sociedade em geral produz sobre elas, tornando suas vidas abjetas (BUTLER, 2006a). Além disso, elas compreendem que a sociedade as culpabiliza pela própria situação de vulnerabilidade. Tal condição também é percebida em suas próprias experiências corporais. Durante as entrevistas, elas mostram várias cicatrizes e apontam certas marcas no corpo, fruto de episódios de violência. Ao sentir no próprio corpo o risco de morte, elas relatam que a morte é o fim de uma trajetória mais ampla de várias outras experiências de violência.

Assim, para elas, o cerne do risco de morte é o preconceito e a discriminação em relação à sua transgressão de gênero e sexualidade. Elas relatam que o preconceito e a discriminação fazem parte de toda a sua existência e apontam que há locais de maior opressão como é o caso da escola, do espaço público e da sua própria casa, quando ainda viviam na casa dos pais. O gráfico 1 evidencia a estrutura de categorias que fazem parte das representações sociais que elas instituem sobre o preconceito e a discriminação associadas ao espaço.

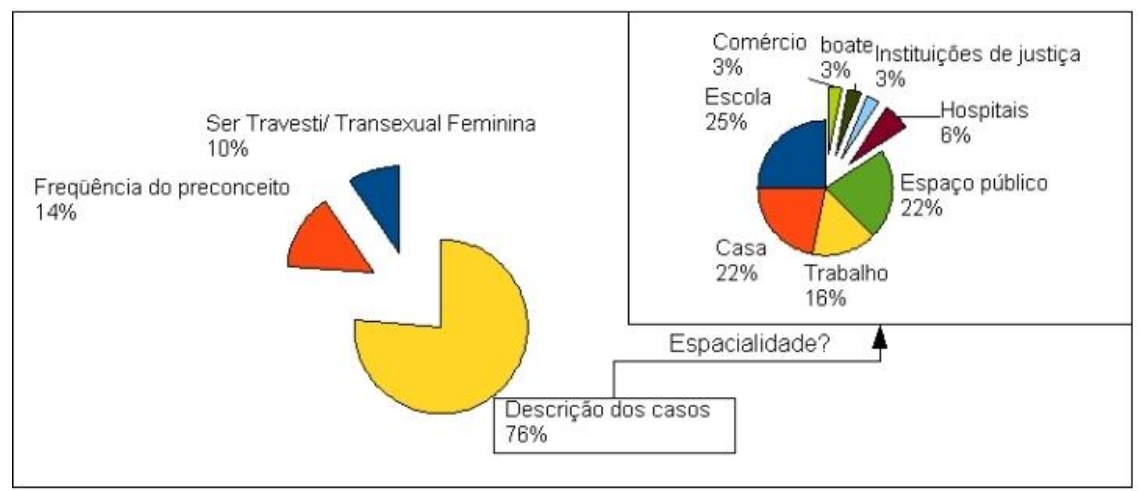

Gráfico 1. Experiências pessoais de preconceito e discriminação sofridas por travestis e transexuais femininas.

\footnotetext{
${ }^{5}$ Todos os nomes são fictícios.
} 
Os espaços apontados nas estruturas discursivas não podem ser compreendidos apenas como locais onde as experiências de preconceito e discriminação acontecem. Para este trabalho, estes são espaços que se conformam na lógica heteronormativa que acabam por constituir o que Silva (2013, p.158-159) chama de espaço interdito. Para ela o espaço se faz de "práticas regulatórias [que] são desempenhadas por aqueles que se julgam dentro da ordem e possuem o poder de exercê-la bem como o de estabelecer as formas com que determinados sujeitos devem ser excluídos". Assim, o espaço não tem um sentido absoluto, mas como James Duncan (1990) argumenta, é um texto lido por determinados sujeitos.

O espaço urbano vivido pelas travestis e transexuais femininas são espaços marcados pelo preconceito e pela discriminação, já que, constantemente, elas são lembradas que estão fora da ordem heteronormativa. Esta lembrança é cotidiana e sistemática, como evidenciam 14\% das evocações mostradas no gráfico 1 sobre a 'frequência do preconceito'. Isso fica claro na fala de Rosa ${ }^{6}$ que afirma o seguinte: "Preconceito para travesti é 24 horas, que você sofre!". Quando Rosa foi provocada a falar de suas experiências de preconceito, imediatamente falou: "Escola, o meio familiar, porque eu apanhei muito da minha mãe e do meu irmão, porque eles queriam que eu fosse homem e homem eu nunca fui”. O preconceito, para elas, está ligado ao fato de assumirem sua transgressão de gênero e sexual, sendo que $10 \%$ das evocações estão relacionadas ao ser travesti ou transexual feminina.

A entrevista de Margarida é exemplar e relata experiências espaciais de casa e da escola já durante a infância e a adolescência. $O$ trecho abaixo sobre estes espaços é uma evidência da tendência discursiva encontrada, trazendo a ideia de que nem a escola e, tampouco a casa, foram lembrados como espaços de proteção e acolhimento.

\footnotetext{
O preconceito começa no momento que eu comecei a me descobrir [referindo-se à sua sexualidade] pelo meu pai. Porque meu pai, se ele visse uma transsexual do outro lado da rua, ele atravessava. O preconceito comecou muito cedo, por causa daquela questão de homem brincar de carrinho e menina de boneca. Eu brincava de show da Xuxa, com uma blusa na cabeça. Você
}

\footnotetext{
${ }^{6}$ Entrevista realizada em Setembro de 2013 em Curitiba no XX Encontro Nacional de Travestis na Luta contra a AIDS (ENTLAIDS).
} 
imagine como ficava meu pai quando via eu daquele jeito. Então, o preconceito comecou muito cedo, antes de eu transformar em transexual. (...) A gente, transexual, comeca a sofrer o preconceito dentro da própria casa, antes mesmo de entrar no próprio meio social, que é a escola. No começo, isso não acontece, todo mundo é igual. Todo mundo é igual até os 6 anos. Depois dos 10, começa adolescência o desenvolvimento da sexualidade. Daí a gente começa a ver que as pessoas vão percebendo. (...) Eu comecei sofrendo preconceito e discriminação quando meu professor queria que eu jogasse futebol. Eu não conseguia jogar futebol, porque eu era delicada, tinha aparência feminina e eu não gostava de jogar futebol. Os meninos aproveitavam naquele tempo para me bater, para me espancar, pra me dar murros, pra me dar chutes e eu não gostava mesmo de futebol. Dai ele [referindo-se ao professor de educação física] olhou na minha cara e disse: vai jogar vôlei porque você é uma menininha mesmo. E daí eu fui jogar vôlei mesmo. Nesse momento, toda a escola comecou a me chamar de viadinho, de menininha, de não sei o que, disso e daquilo. Nós não somos respeitadas dentro das escolas. (Entrevista realizada com Margarida, em Curitiba, em Setembro, no XX ENTLAIDS)

Margarida continua seu relato, trazendo suas experiências já em fase adulta, onde aparece o sofrimento no trabalho e em instituições de justiça:

(...) Depois eu tive preconceito dentro do ambiente de trabalho. Eu sempre tive que trabalhar o dobro porque eu era transexual. O que uma pessoa fazia, eu tinha que fazer o dobro. Se uma pessoa corria $1 \mathrm{~km}$, eu tinha que correr $2 \mathrm{~km}$. Então, isso aí mostra o reflexo do tratamento de você ser o que você é. Depois eu tive muito preconceito institucional quando fui pra denunciar essas violências que sofri e eles simplesmente me ignoraram. Ignoraram a minha fala, ignoraram a minha condição. Disseram simplesmente para mim [referindo-se ass policiais]: arruma um trabalho, vai trabalhar, você sofreu essa violência porque você estava no lugar errado, na hora errada! Então eu disse pra ele: pois é, agora eu queria que você me dissesse como que eu faço pra sair desse lugar? [referindo-se ao local de prostituição]. Dai ele disse: isso não é problema meu. (...) Como eu te disse, a vida é uma só e você tem que viver intensamente dia após dia, porque o futuro só Deus sabe. Com relação a nós que somos travestis, transexuais, se tiver um futuro. (...) A exclusão social parte de todos os segmentos, de todos os lugares e viver na exclusão é a violência que está em todos os lugares (Entrevista realizada com Margarida, em Curitiba, em Setembro, no XX ENTLAIDS) 
Os espaços que compõem a cidade são evocados nas experiências de preconceito e da discriminação. Assim, a cidade vai paulatinamente sendo lida e interpretada como composta de espaços multiescalares de interdição.

A estrutura discursiva que o grupo de entrevistadas apresenta é a de que o próprio preconceito e a discriminação são tipos de violência psicológica que iniciam um processo que se agrava. $\mathrm{O}$ gráfico 2 evidencia a ligação entre os tipos de violência que elas enumeram e as dificuldades de obter canais de queixa sobre a violência sofrida.

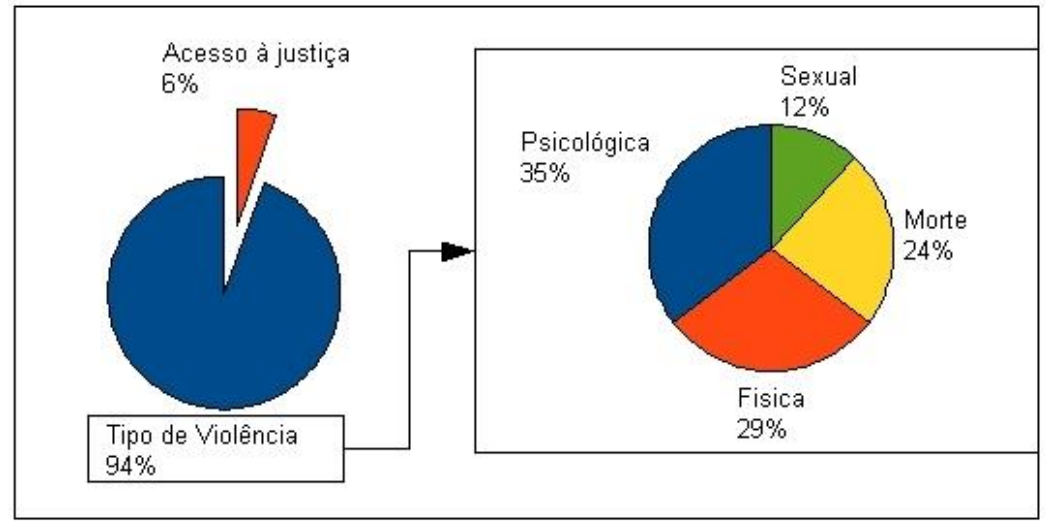

Gráfico 2. Formas de violência retratadas por travestis e transexuais femininas.

Quando elas se referem à violência psicológica, seus relatos estão em torno da negação de sua identidade de gênero e sexual. Margarida diz que

a pior de todas as violências é te negar o direito de ser quem você é. Eu acho que as pessoas dizerem o que eu tenho que fazer com o men sexo ou a roupa que eu tenho que vestir, ou ser aprovada ou reprovada por que eu sou quem eu sou, eu acho que essa é a pior de todas as violências. Eu suporto um murro, eu suporto um tapa, eu suporto um palavrão. O que eu não suporto é simplesmente eu não ser reconhecida e respeitada por ser quem eu sou. Eu quero ser reconhecida. Eu acho que a maior de todas as violências é essa negação da minha pessoa como ser humano (Entrevista realizada com Margarida, em Setembro de 2013, em Curitiba, no XX ENTLAIDS) 
A violência física e a morte estão diretamente conectadas com o reconhecimento de sua vulnerabilidade social e econômica em torno da atividade de prostituição. Elas sentem que estão desprotegidas e são alvos fáceis de vários tipos de pessoas. O trecho que segue é um modelo da articulação entre violência física e morte, relatado por Iris:

[o grupo sofre] todo tipo de violência. Porque a gente que precisa da rua [referindo-se à atividade de prostituição], a gente tá ali à mercê. A gente não sabe se vai voltar pra casa, se a pessoa que a gente tá entrando dentro do carro, se vai trazer a gente de volta viva, ou vai largar lá já morta. Então, a gente não tem segurança nenhuma. (Entrevista realizada com Iris, em Abril de 2014, em Ponta Grossa, no Grupo Renascer.)

A falta de acesso à justiça é parte da estrutura discursiva que institui as representações sociais das travestis e transexuais femininas em relação à violência e morte. Para Tulipa "a pior violência é a injustiça, o descaso, a falta de conhecimento de quem toma a frente dessa situação". (Entrevista realizada com Tulipa, em Outubro de 2013, em Londrina, na casa da Margarida.)

Quando solicitadas a realizar uma avaliação sobre suas vidas relacionadas a sua situação de violência é possível observar que elas constituem uma relação lógica entre as categorias discursivas instituindo uma clara representação social de sua vulnerabilidade à violência e à morte como pode ser visto no gráfico 3.

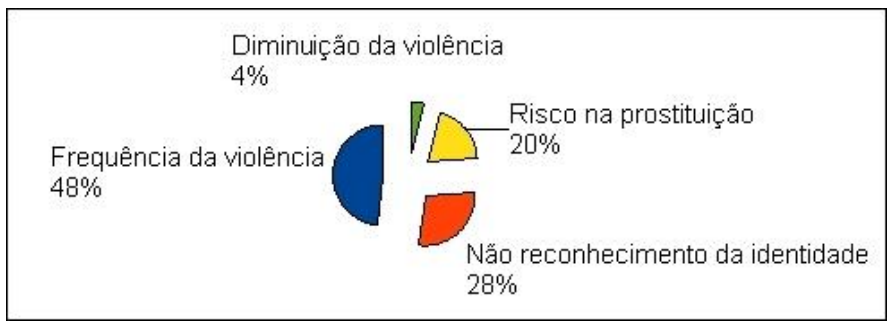

Gráfico 3. Avaliação sobre a violência na vida das travestis e transexuais femininas.

A estrutura discursiva observa que a não aceitação de sua identidade de gênero e sexual cria uma situação de exclusão que as coloca em risco de exercício da prostituição como alternativa de sobrevivência e isso faz com que a violência se coloque em suas vidas como algo frequente. Contudo, as 
entrevistadas mais velhas argumentam que, se comparado à duas décadas atrás, há diminuição da violência por parte de policiais. Louro (2008) deixa claro que as normas regulatórias da sociedade imprimem as marcas nos corpos. Para as travestis e transexuais femininas as marcas de violência são nítidas, bem como o reconhecimento de uma trajetória comum do grupo que articula a negação de sua existência dentro dos parâmetros estabelecidos socialmente como normais. Jasmim traz um trecho de entrevista que ilustra esta representação:

Diário, as violências. Tem a psicológica que nego passa no ônibus gritando, xingando a gente. É gente que taca as coisas em você. É gente que para o carro, chama você só pra te dar uma extintorzada na cara. Um monte de gente que eu já vi voltar com a cara branca, parecendo um fantasminha. Eu acho que a transexual tá exposta a todo tipo de violência, desde a psicológica, moral e física. Porque ela tá ali. Do mesmo jeito que pode chegar uma pessoa boa, levar ela, fazer tudo com ela e pagar ela bonitinha, pode chegar uma pessoa má, obrigar ela, levar ela pro meio do mato e fazer tudo porque ela não tem nem o direito de morrer dignamente. Ela é um lixo. Nem um lixo ela é, porque um lixo é definido e ela não é. Eu morro de medo, depois de tudo que eu passei, eu tive que voltar né [referindo-se à atividade de prostituição]. Então, a gente tem medo porque eu sei que tudo que eu passei pode se tornar verdadeiro de novo. Me dá medo pensar que eu não vou aguentar dessa vez. Porque mesmo se eu sofrer uma agressão dessa e sobreviver, eu não sei se eu vou conseguir viver depois, porque com isso que me aconteceu já é difícil. (Entrevista realizada com Jasmim, em Outubro de 2013, em Londrina, na casa da Margarida.)

Esta avaliação da violência em sua vida está associada à imagem que a sociedade em geral cria sobre a morte de pessoas do seu grupo. Nas suas experiências concretas relatadas, a ideia que a sociedade faz das travestis e transexuais femininas pode ser visualizada no gráfico 4 .

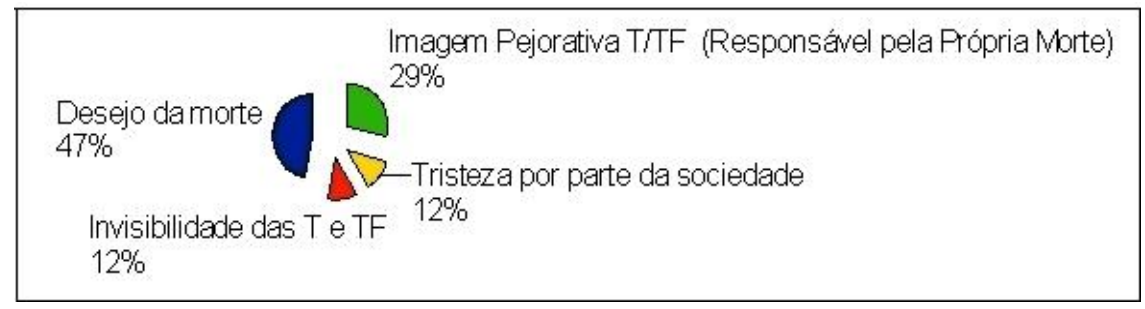

Gráfico 4. Imagem da sociedade sobre morte de travestis e transexuais femininas. 
A análise evidencia que na maioria das falas há uma situação de oposição entre o grupo de pessoas entrevistadas e a sociedade. Suas experiências concretas levam a considerar apenas $12 \%$ de evocações que trariam a ideia de que a sociedade poderia sentir algum pesar pela morte de uma travesti ou transexual feminina. Ao contrário, todas as outras evocações estruturaram categorias discursivas que coloca em lados opostos a sociedade e o grupo. Ao considerar as categorias 'Desejo da Morte' (47\%), 'Imagem Pejorativa T/TF ' (29\%) e 'Invisibilidade da Travesti' (12\%) podemos afirmar que 88\% das evocações expressam sérios conflitos.

As travestis e transexuais femininas entrevistadas consideram que a imagem pejorativa que a sociedade faz delas impulsiona o desejo de que elas não existam, e assim, sua morte passa desapercebida. Margarida, em um trecho de sua entrevista, traz uma fala exemplar do grupo:

Existe uma higienização pessoal, que pra sociedade é extremamente normal, ver uma travesti morta. Eu acho que é uma imagem que sempre vai ser normal. A morte vai estar sempre ligada ao estigma da prostituição, da promiscuidade. Eu acho que é isso que justifica toda essa violência. É o fato de as pessoas não entenderem o porquê que essas pessoas estão ali à mercê de tudo isso. Não se tem interesse dos órgãos de segurança de estar esclarecendo o real motivo daquela morte. Então, eu acredito que a sociedade aplaude quando morre. A sociedade aplaude violência contra travestis e transexuais. Quero que dê ênfase a isso, porque é a realidade. É a realidade e você vai ver isso. (...) A sociedade aplaude sim que outras pessoas façam o serviço sujo que elas gostariam que fosse realizado, que é a exterminação de nós travestis e transexuais (Entrevista realizada com Margarida, em Setembro de 2013, em Curitiba, no XX ENTLAIDS.)

Os relatos de experiências limite constituíram duas categorias complementares. Uma delas que relata o tipo de violência sofrida e o outro que congrega os locais de ocorrência desta experiência em que a fronteira entre a morte e a vida era tênue. De forma contundente, aparece o território da prostituição e a rua como sendo constituídos do fenômeno de morte.

Quando questionadas sobre suas maiores preocupações em sua avaliação sobre a violência em suas vidas, as travestis e transexuais femininas evidenciam que suas experiências concretas as levam a temer a morte, associada com a tortura e com a violência física. 


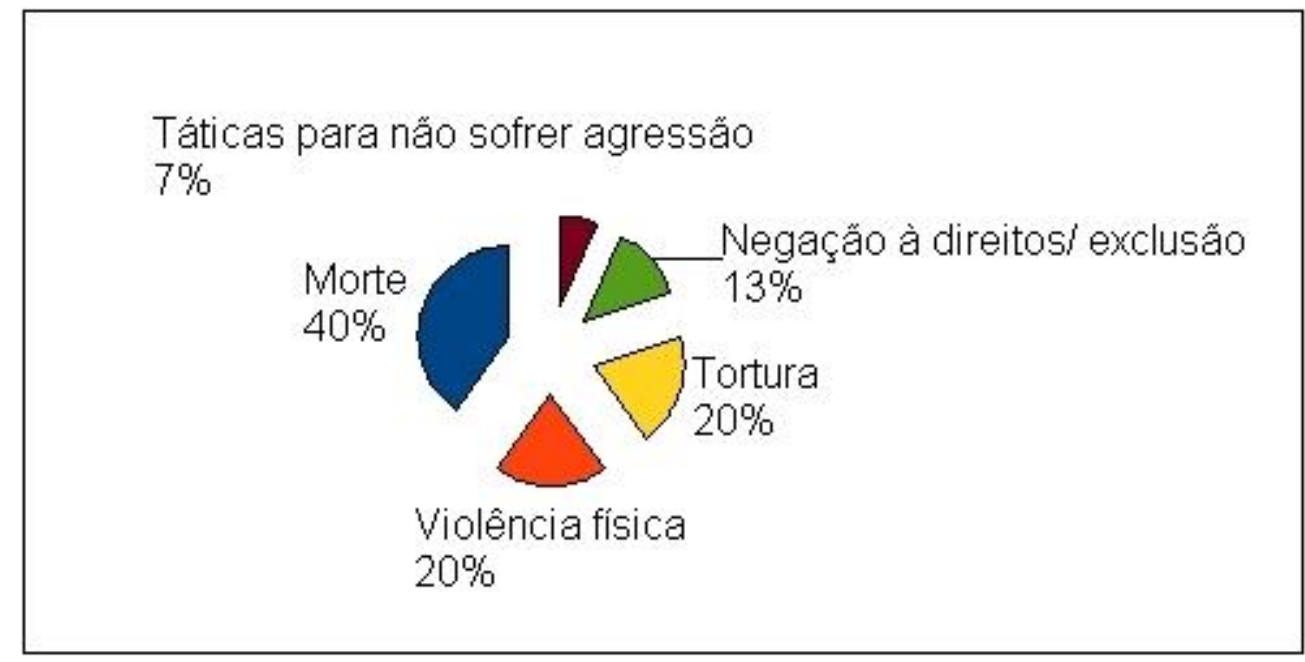

Gráfico 5. Temor de formas de violência por parte de travestis e transexuais femininas.

Ao contexto das travestis e transexuais femininas, Cabral, Silva e Ornat (2013) apontam que os crimes com requinte fazem parte das estatísticas de mortes do grupo. Os autores ainda apontam que a espacialidade em que ocorre o crime é de fundamental importância para o assassino executar a vítima de uma maneira ou outra. Em espacialidades onde há um maior fluxo de pessoas a execução da vítima é rápida, com a utilização de arma de fogo. No entanto, quando o assassino tem o privilégio de estar em uma espacialidade de menor fluxo ou ausência de pessoas, a vítima é executada com um requinte de crueldade, o qual é fortemente embebido de violência psicológica e tortura física.

Iris cria o desejo de se livrar da morte associada à tortura dizendo: "eu já preferia o tiro que a gente não sente. Prefiro isso do que faca, estrangulamento ou tirar uma parte do corpo, tirando devagarinho, cortando, braço, perna né". (Entrevista realizada com Iris, em Abril de 2014, em Ponta Grossa, no Grupo Renascer).

O temor de crimes violentos associados à transfobia é comum entre elas. Apesar de todo o temor da morte associada à tortura, há ainda que se considerar que elas lutam, criam estratégias para não serem alvos fáceis aos criminosos e também apontam para a necessidade de superar a negação de suas vidas. Margarida lembra que morrer, para ela, significa mais do que a morte física, dizendo que a "exclusão 
em vida eu acho que é a pior de todas as coisas" (Entrevista realizada com Margarida, em Setembro de 2013, em Curitiba, no XX ENTLAIDS).

O discurso das pessoas entrevistadas quando elas foram provocadas a relacionar espaços de maior vulnerabilidade à morte, há a associação entre espaço de prostituição e espaço público, como mostra o gráfico 6.

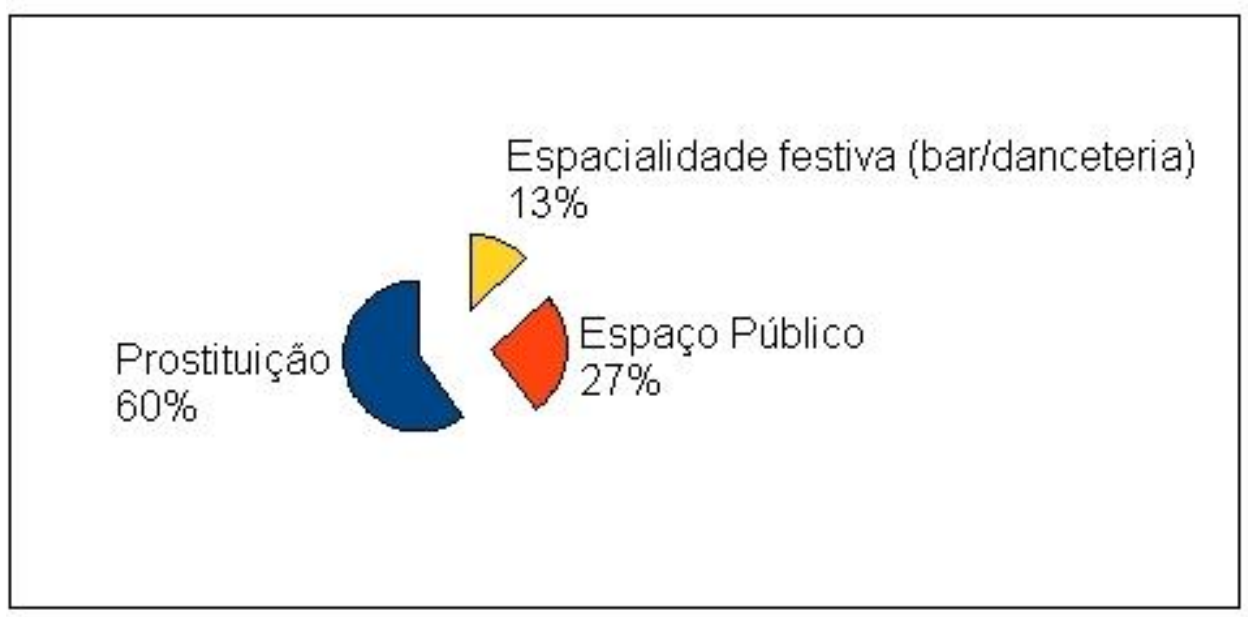

Gráfico 6. Espaços de vulnerabilidade à morte na interpretação de travestis e transexuais femininas.

A área de prostituição, em geral, um território urbano na concepção de Ornat (2008), é o espaço de maior associação com a morte, notadamente a morte violenta. Azaleia diz que "o momento de trabalho, quando precisamos estar nas ruas, correndo atrás do nosso ganha pão, da nossa sobrevivência. Esse é o local mais crítico para sermos violentadas e assassinadas". (Entrevista realizada com Azaleia, em Agosto de 2013, em Curitiba, no Trans Grupo Marcela Prado). As outras entrevistadas fizeram o mesmo tipo de associação. Isso traz mais um elemento que se soma à definição do território paradoxal ${ }^{7}$ já proposto por Ornat (2013).

\footnotetext{
${ }^{7}$ A proposta conceitual de Ornat (2013) sobre o território paradoxal da prostituição travesti etá baseada em Rose (1993) em sua teoria do espaço paradoxal.
} 
Segundo o Ornat (2013) o território da prostituição não é apenas um local de conquista de condições financeiras de sobrevivência, mas um espaço que viabiliza a manutenção identitária do grupo de travestis. É também ali que elas se sentem aceitas pela sociedade, podendo expressar sua feminilidade e despertando o desejo. Contudo, paradoxalmente o mesmo espaço que lhes permite viver, é também o espaço que se faz de suas representações sociais de vulnerabilidade à morte.

Por fim, as experiências concretas do grupo de entrevistadas sobre a vivência de agressões graves que as colocaram em um limite tênue entre a vida e a morte evidenciam sua ideia sobre o atendimento da saúde, como pode ser visto no gráfico 7.

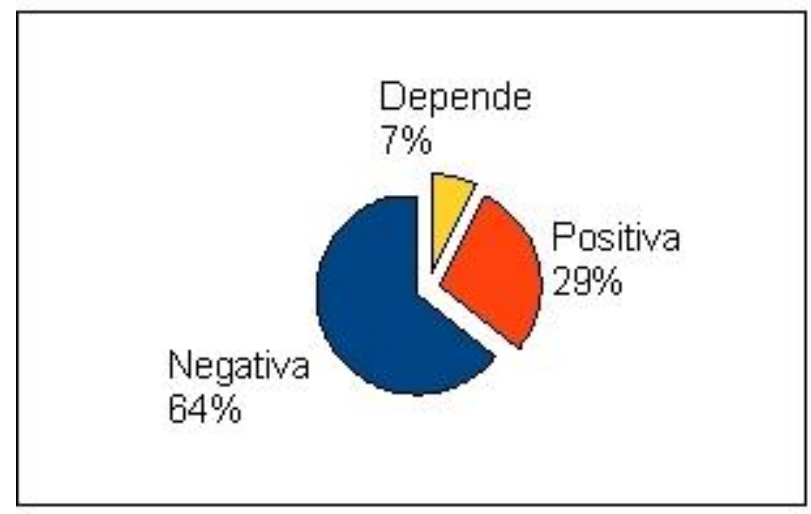

Gráfico 7. Tipos de experiências de atendimento em instituições de saúde.

O acesso à saúde, é bastante dificultado às travestis e transexuais femininas. Quando elas sofrem algum tipo de ato de violência que as coloca em uma situação de limite, é inevitável que as pessoas possam prescindir deste tipo de atendimento. Das evocações do grupo, 64\% apresentam experiências negativas quando necessitaram de atendimento, 29\% das evocações constituíram uma categoria positiva e 7\% alega que teve situações positivas devido a postura de funcionários bem treinados para receber pessoas como elas.

A ideia do atendimento positivo (29\%) refere-se às conquistas do nome social e o respeito que elas obtiveram em instituições de saúde pela sua identidade como travesti ou transexual feminina. Apesar 
da conquista legal, a realidade cotidiana ainda gera sofrimento pelo despreparo das pessoas que fazem o atendimento direto ao público. Azaleia, alega que:

nos casos que eu sei de meninas que sofreram violência, elas são levadas para o pronto atendimento dos hospitais. Elas são entregues lá, são desrespeitadas, são colocadas nas alas masculinas. Muitas meninas que eu conheco que estão vivendo com HIV/AIDS precisam de hospitais de referência para esse atendimento e elas são colocadas lá, como qualquer outra pessoa. (...) Por mais que algumas delas tenham se recuperado no atendimento hospitalar, elas sempre saem descontentes do atendimento que tiveram. O que pega mesmo é a questão do desrespeito à identidade dessas pessoas [referindo-se à identidade de gênero e sexual]. Isso agrava muitos problemas de saúde. Eu costumo dizer em todos os setores que a partir do momento que você, é desrespeitada, tudo piora. Em vez de ajudar a tratar aquela pessoa, você está prejudicando muito mais, porque você está afetando o lado emocional dela. A chance de recuperação de qualquer violência física é diminuída, pode levar pessoas à morte. (Entrevista realizada com Azaleia, em Agosto de 2013, em Curitiba, no Trans Grupo Marcela Prado.)

\section{A Morte como Elemento da Vida Cotidiana e as Representações Sociais sobre Futuro: a luta pelo direito de envelhecer}

Valentine (1993) elabora sua teoria da relação entre espaço e heteronormatividade, argumentando que o espaço é componente da norma, mas também pode ser um elemento de subversão. Se na seção anterior inferimos que a morte de travestis e transexuais está vinculada à cidade heteronormativa, precisamos ainda explorar as fissuras dessa ordem e o crescimento da resistência ao destino fatídico que se desenha no seu cotidiano.

O envelhecimento é uma fase da vida que é pouco preparada para ser uma realidade concreta pelas pessoas entrevistadas. Quando elas foram questionadas sobre como elas projetavam seu envelhecimento, ficou constatado que $41 \%$ das evocações constituíram a categoria de 'não projeta a velhice' e 59\% das evocações evidencia que elas criam expectativas para o processo de envelhecimento. 
O gráfico 8 evidencia que, mesmo entre aquelas que criam expectativas sobre o envelhecimento, as representações de medo e peso da idade são marcantes.

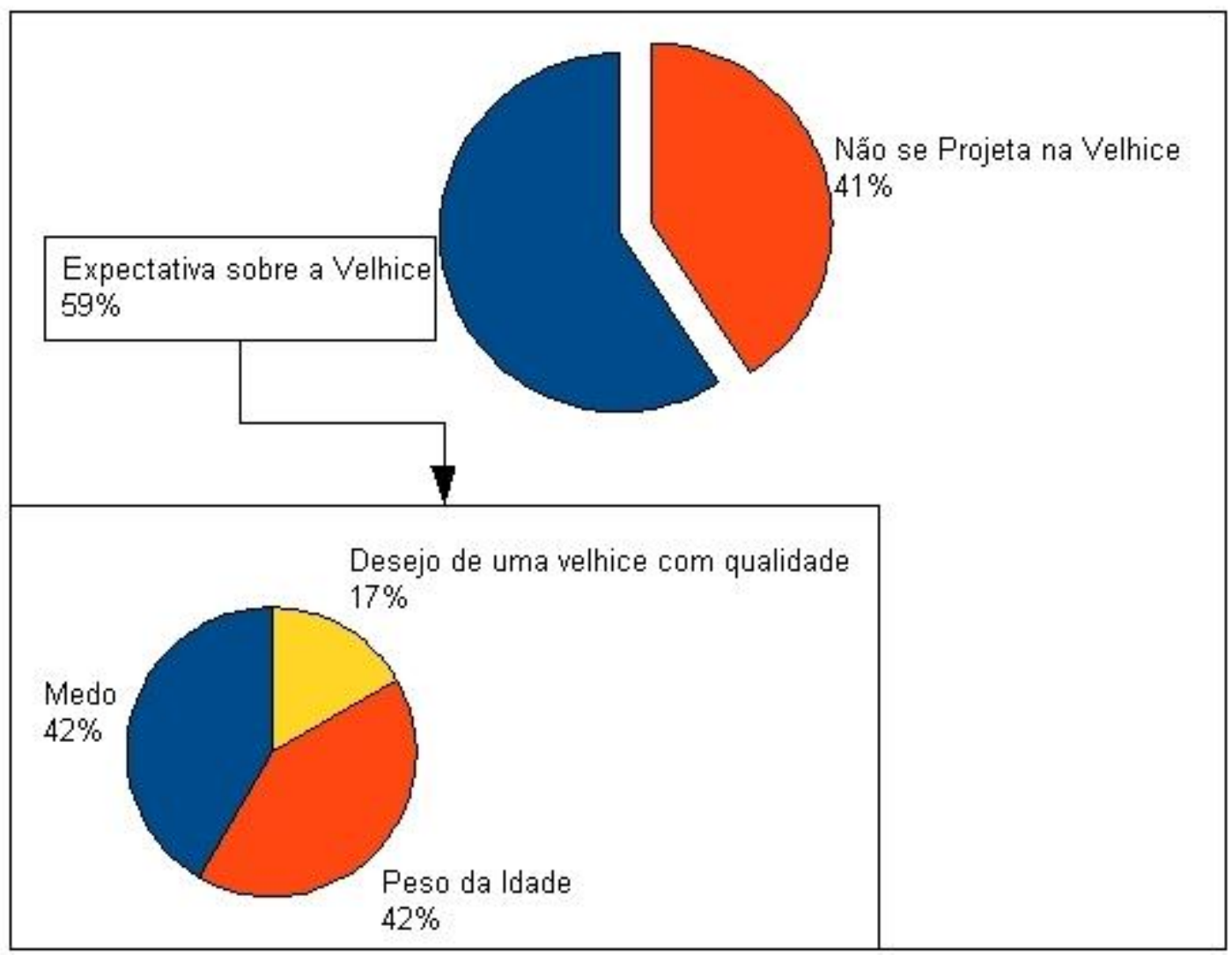

Gráfico 8. Projeção do envelhecimento por parte de travestis e transexuais femininas.

Como a vulnerabilidade à morte precoce é algo comum ao grupo, muitas delas não projetam em si mesmas um processo de envelhecimento, como pode ser visto no trecho de relato de Azaleia:

Não [referindo-se ao fato de não projetar seu envelhecimento]. Primeiro, porque eu tenho medo da velhice. Não trabalhei isso na minha cabeça. Talvez pelo medo da morte e do grande número de violência que a nossa população sofre. Até pelas questões naturais, porque eu costumo dizer hoje eu com 40 anos eu me sinto com 60. Isso porque a carga de vida que eu tive me faz sentir esse peso da vida. Isso me causa muitos danos a minha saúde e claro, tenho o medo da violência, de sair e ser assassinada ou, até mesmo dentro de sua própria casa. Ma claro que tenho medo da velhice. Porque eu nunca pensei em envelhecer. (Entrevista realizada com Azaleia, em Agosto de 2013, em Curitiba, no Trans Grupo Marcela Prado.) 
Mesmo aquelas que dizem ter expectativas sobre o processo de envelhecimento, esta fase da vida é vista como temerosa. São comuns os relatos de casos de amigas que tiveram uma velhice desamparada. Um aspecto importante é perceber que a velhice não é um dado apenas cronológico. Os discursos das travestis e transexuais evidenciam que a fase de entrada dos 40 anos já mostra aquilo que elas chamam de 'peso da idade'. As travestis e transexuais vivem a vida transformando o corpo e muito atentas à estética como visto em Pelúcio (2005), Benedetti (2005). Portanto, ser velha nas representações sociais das travestis e transexuais femininas, não é o mesmo que para outros grupos. Violeta fala sobre o peso de envelhecer associada ao fato de ser uma travesti, referindo-se a um limite de idade de sessenta anos.

Olha não gostaria de chegar aos 60, mas se for a permissão de Deus, fazer o que. Imagina, já é travesti e ainda velha? É pra acabá! Eu acho que já deu. Já vivi aquilo que tinha de viver. Acho que a idade tem um limite como todas. Acho que a idade pesa mais para uma travesti do que para um hétero, bem mais. (Entrevista realizada com Violeta, em Setembro de 2013, em Curitiba, no XX ENTLAIDS.)

Mesmo assim, há entre elas o 'desejo de uma velhice com qualidade'. Este desejo se relaciona as lutas que às entrevistadas realizam hoje, bem como as questões estéticas de seus corpos no futuro. 0 trecho de entrevista de Margarida revela este desejo.

Eu vou estar idosa, eu acho envelhecer com saúde. Dignidade te faz você melhor, e eu acho que tantas pessoas nesse encontro, que são pessoas já com sua maturidade, com a sua vivência, isso só dignifica, dignifica o ser humano, dignifica tudo aquilo que acredita, os nossos ideais que as coisas melhoram dia a apos dia, nos da forca de envelhecer eu quero um dia assim tá velhinha, bonita cheia de botox (risos) viver da melhor forma possível minha vida que eu acho que é mais importante, eu quero tá bonita, gostosa que eu acho que isso é um direito de qualquer uma, mas assim dentro das minhas condições, das minhas possibilidades, o que vai me dignificar a minha velhice, é a minha qualidade de vida hoje, no agora, então se eu lutar agora eu posso ter paz amanhã, então eu acho que a luta, começa hoje pra que amanhã eu posso tá vivenciando o que eu desejo, que é uma velhice (Entrevista realizada com Margarida, em Setembro de 2013, em Curitiba, no XX ENTLAIDS.) 
O desejo de uma velhice tranquila pode se realizar, na medida em que ações concretas são realizadas e as falas sobre como elas se preparam concretamente para uma velhice tranquila gerou $2,41 \%$ do total das evocações. Duas categorias puderam ser constituídas. A primeira, com $67 \%$, reúne aquelas que afirmam que não estão realizando ações concretas para viver o período da velhice e 33\% relatam suas estratégias para enfrentar o envelhecimento.

O trecho da entrevista de Azaleia evidencia que a falta de perspectiva de futuro faz com que as travestis e transexuais femininas vivam apenas o tempo presente.

O que eu ganhei hoje, eu tenho que gastar hoje! Justamente por essa falta de perspectiva de envelhecer. Eu acho que eu não posso me privar de ter uma cama boa, de ter um carro bom, de ter uma casa boa, de comer bem hoje. Isso porque talvez essa velhice talvez possa não chegar. Nunca guardei dinheiro na minha vida. Nunca consegui guardar. Até porque eu nunca ganhei tanto dinheiro assim, nem com a prostituicão, nem com os trabalhos que eu tive. Todo o dinheiro que eu ganhei foi para me manter, sempre dentro do conforto que eu sempre quis. Então, para mim era isso que importava e ainda hoje importa. Eu ter o conforto hoje e viver bem. Porque como eu falei, a perspectiva e envelhecer e como vai ser isso depois eu não parei para pensar. (Entrevista realizada com Azaleia, em Agosto de 2013, em Curitiba, no Trans Grupo Marcela Prado.)

A categoria que reuniu evocações sobre o preparo para a velhice trouxe a preocupação com bens materiais como casa própria e cuidados preventivos com a saúde, como é o relato de Violeta.

Eu guardo dinheiro no banco. Hoje eu tenho uma qualidade de vida a mais, então sempre quando sobra um dinheiro a mais eu guardo. Eu me procuro em me preparar para quando chegar um certo tempo, para não precisar mais trabalhar, não fazer nada, ter meu carro, minha casa e não precisar mais fazer isso [referindo-se à atividade de prostituição]. Eu sempre faço exame de rotina, de cuidados. Estou sempre atenta à minha saúde. Hoje eu viso a saúde né, coisa que eu não via antes. Não me importava, mas hoje eu viso bastante. (Entrevista realizada com Violeta, em Setembro de 2013, em Curitiba, no XX ENTLAIDS.)

Quando elas foram questionadas sobre suas expectativas de futuro, as pessoas do grupo realizaram falas que representam $1,92 \%$ do total de 622 evocações que compuseram a totalidade das falas do 
grupo entrevistado. Estas evocações foram agrupadas em duas categorias que, por sua vez, apresentam eixos internos. 0 gráfico 9 evidencia o esquema representacional.

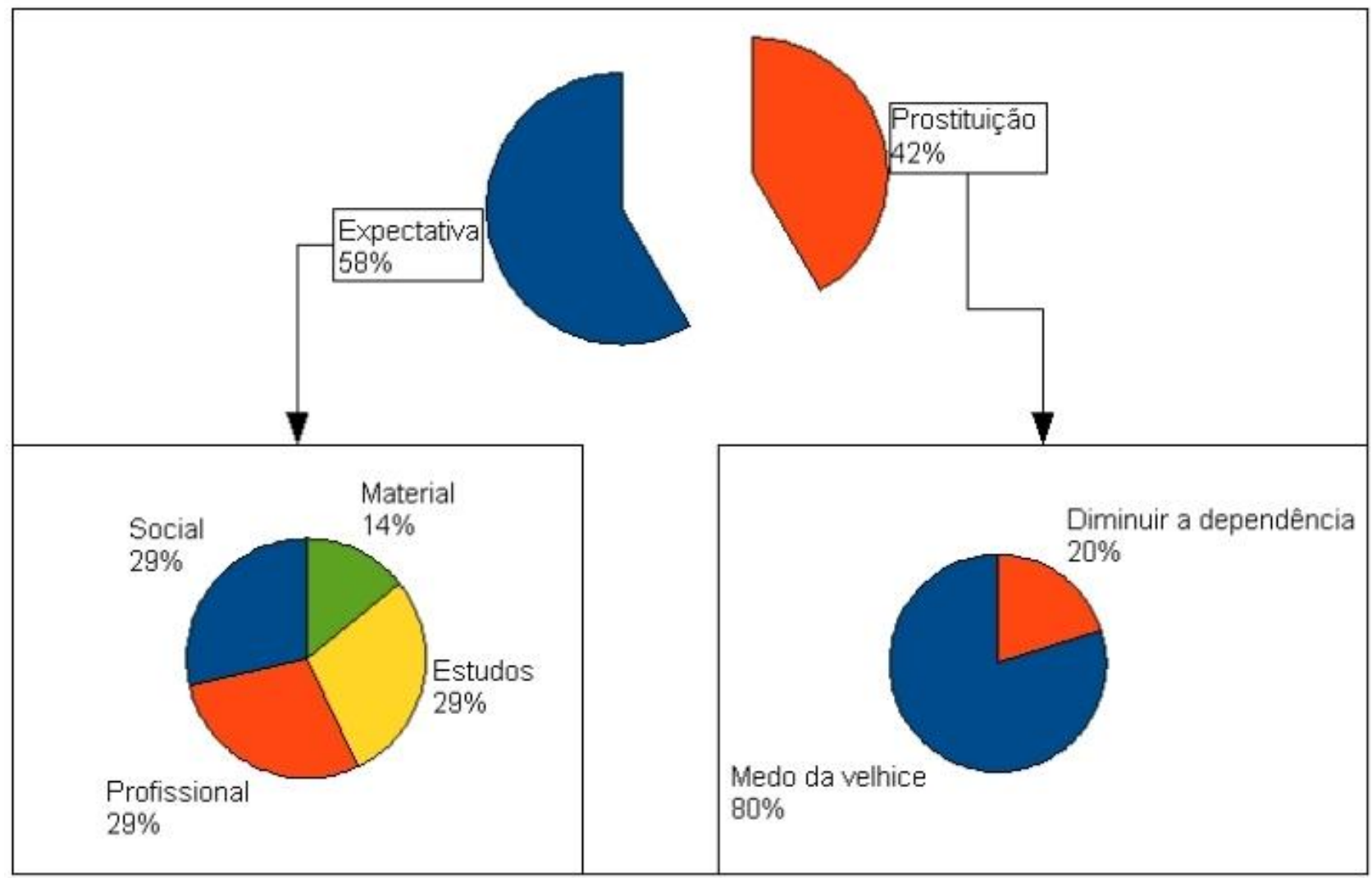

Gráfico 9. Expectativas de futuro relatadas por travestis e transexuais femininas.

O imaginar o futuro está associado aos sonhos e expectativas e à realidade de não poder mais sobreviver da atividade de prostituição. Elas alegam que a atividade de prostituição é competitiva e necessita ser alimentada pela sedução da juventude e pela beleza do corpo perfeito. Desta forma, as travestis e transexuais femininas têm muito medo de envelhecer na prostituição, na medida em que seus corpos envelhecem a as novas travestis e transexuais surgem. Azaleia aponta o cenário competitivo, movido pela novidade e beleza dos corpos mais jovens.

o medo das travestis, justamente de envelhecer talvez seja isso também, por quê como que eu vou me prostituir? até porque dia a dia, principalmente hoje em dia que essas novas safras que estão vindo muito precocemente, você envelhece muito mais cedo dentro da prostituição, antigamente as travestis né ... existiam as meninas que eram menores de idade se prostituindo mas a maioria 
era maior de idade, de 18, 20, 25.... 30 anos você já era velha na prostituicão, antigamente hoje, com 25 você já é velha na prostituição, é igual carreira de modelo, ela é meteórica, então hoje as meninas estão se assumindo mais cedo, aos 13, 14 anos já virando travesti, transformando seus corpos, caindo na prostituição precocemente, saindo de casa, para se prostituir, e aos 18,20 anos já estão envelhecidas para a prostituição, porque já vai vir outra safra de 15,16 e é mais ou menos isso. (Entrevista realizada com Azaleia, em Agosto de 2013, em Curitiba, no Trans Grupo Marcela Prado.)

A partir deste cenário, o grupo reconhece o limite da dependência da prostituição como possibilidade de sustento financeiro no futuro e, por isso, sentem medo de não constituir outras alternativas fora do universo da prostituição que foi vivido intensamente durante a fase jovem. A decadência física faz parte da ideia de envelhecer e não ter mais como sobreviver na atividade de prostituição, como nos diz Iris.

Eu tenho 42 anos. Tô estudando e não dependo muito da rua [a rua nesse contexto é sinônimo de atividade de prostituição]. Espero quanto menos depender dela, vai ser melhor. Até mesmo porque, nós travestis, temos prazo de validade. A minha validade já se esgotou e por isso que eu tô me dedicando ao estudo. Eu quero me formar, eu quero ter o meu trabalho estável e ficar quitenha, e curtir a minha velhice. (Entrevista realizada com Iris, em Abril de 2014, em Ponta Grossa, no Grupo Renascer.)

As expectativas em relação ao futuro somam 58\% das evocações e evidenciam que, apesar das dificuldades, as travestis e transexuais ainda sonham com a possibilidade de uma vida confortável e com dignidade. Elas relatam ter expectativa em poder vivenciar uma sociedade mais acolhedora com relação à orientação de gênero e sexualidade, pois isso traria mais chances de estudos e oportunidades de trabalho o que, consequentemente, lhes traria uma vida material mais confortável e segura. Margarida em sua fala traz um relato significativo desta tendência.

Eu acredito num Brasil igualitário, em um pais que ainda venha respeitar o ser humano pelos seus valores, não pela roupa que se veste. Eu acredito que um ser humano não pode ser julgado pela cor, pela estatura do corpo, pelo padrão de beleza. Eu acredito que a gente tem que ser valorizada pelo que a gente é. Eu acho que é essa expectativa que eu quero. Eu quero poder dizer 
que eu estava certa, que eu vivi a minha vida da melhor maneira possivel e envelheci dignamente. Não estou aqui dependendo do serviço social e sou amada, tenho aquilo que eu busquei. Seja pouco ou muitos milhões ou um salário que me dignifique no final do mês. Mas que eu não dependa de ninguém, não dependa de um marido, de uma assistência social, de uma cesta básica ou de uma doação. Eu morro de medo. O meu maior medo é de terminar como muitas amigas minhas terminaram, precisando das outras [referindo-se às outras travestis mais jovens]. Eu acho que isso é injusto, sabe. Você viver uma vida toda, você acreditar, você desejar e você não ser atendido, não ter esse desejo realizado. (...) É isso, eu quero é uma expectativa de vida e que seja longa. (Entrevista realizada com Margarida, em Setembro de 2013, em Curitiba, no XX ENTLAIDS.)

Quando elas foram provocadas a falar sobre o pensamento sobre sua própria morte, elas revelam que a morte é um tema que permeia a existência do grupo e que este fenômeno influencia no modo de sua existência imediata. Azaleia argumenta que

a falta de perspectiva, faz não pensar na velhice. Você utiliza todo recurso que você ganha hoje para viver o hoje. (...) Mas eu acredito que inconscientemente é assim mesmo que as pessoas norteiam suas vidas, que elas têm pavor e sabem que vão morrer mais jovens que as demais pessoas. Até porque, se você fizer um levantamento, você vai encontrar muito poucas travestis na terceira idade. Então, isso tudo é um reflexo para vida das meninas. Não tem tantas travestis na terceira idade que elas conheçam e que contem as suas histórias. Parece que as travestis e transexuais são determinas a não chegar à terceira idade. (Entrevista realizada com Azaleia, em Agosto de 2013, em Curitiba, no Trans Grupo Marcela Prado.)

A ideia que elas fazem de sua morte foram organizadas em duas importantes categorias discursivas. Uma delas girou em torno das expectativas que elas nutriam sobre o que as pessoas pensariam quando soubessem de sua morte. A outra categoria reuniu o desejo de que sua morte fosse tranquila, sem violência, de forma diferente das notícias de morte de travestis e transexuais femininas conhecidas. 


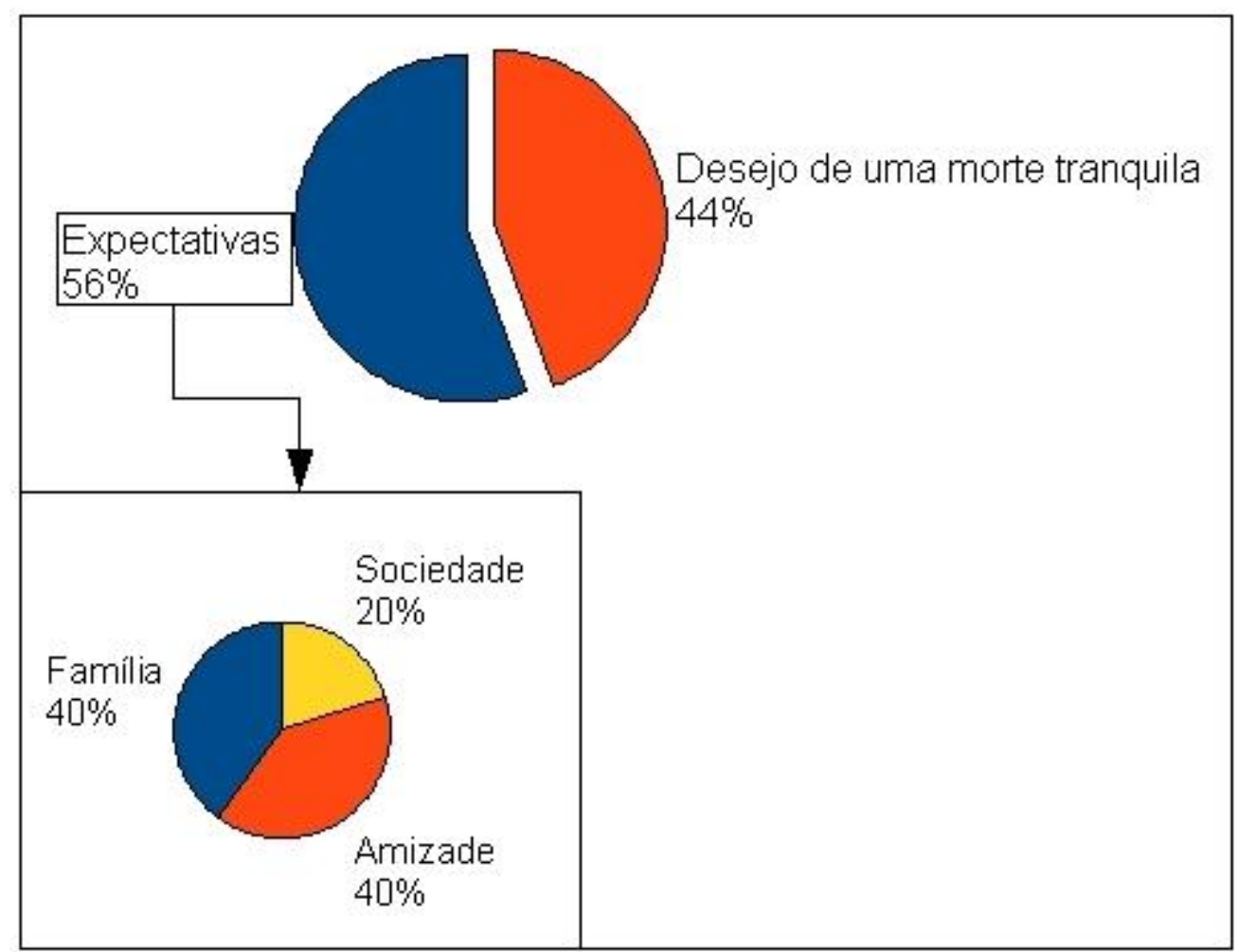

Gráfico 10. Ideia de morte de si

A presença constante da morte em seu cotidiano e a consciência que elas são vulneráveis à morte violenta faz com que o 'desejo de uma morte tranquila' esteja ligado em oposição às suas experiências concretas, como fala Violeta: "Eu quero dormir e não acordar mais. Minha morte eu desejaria assim, deitar numa cama para dormir e não acordar mais. Não quero sofrer em hospitais, nem sofrer na rua, ser encontrada morta, espancada, esfaqueada em uma rua qualquer". (Entrevista realizada com Violeta, em Setembro de 2013, em Curitiba, no XX ENTLAIDS.)

Os discursos das travestis e transexuais entrevistadas trouxeram evocações sobre as expectativas do sentimento de pessoas que viriam a saber de sua morte. Os amigos são pessoas com quem elas mantêm identificação e o sentimento seria de perda de alguém importante. A família é lembrada com ambiguidade, já que as travestis e transexuais vivem vários conflitos ao longo da vida com o núcleo familiar. A sociedade em geral, para elas, teria a interpretação de higienização de alguém que não faria falta para ninguém. $\mathrm{O}$ trecho de entrevista de Violeta expressa a tendência discursiva do grupo: 
Eu acho que eles ficariam muito tristes [referindo-se aos familiares\}. Hoje eles ficariam tristes. Se fosse outro tempo, não. Já passei por morta por várias vezes para eles. A minha mãe já foi no cemitério ascender vela pra mim, achando que eu tava morta. Então eu acho o que eles sofreriam muito, mesmo que eu não convivi muito tempo com eles, mas eles sofreriam muito. Mas deixar os amigos é lamentável. Você veja, eu perdi um amigo agora, que era gay, que era como se fosse um filho pra mim. Você veja, ele tinha 21 anos, era de dentro da minha casa e eu cuidava dele. A família dele é homofóbica devido a religião deles. Ele se matou. Foi muito triste assim, saber que eu pedi um amigo. Da mesma forma eles ficariam tristes se soubessem que iam me perder. A gente discutia muito sobre isso, de quem ia primeira. Se eu ia primeiro ou ele. De repente, ele tirou a própria vida. Ele era lindo. Mas para a sociedade [referindo-se à morte de uma travesti ou transexual femininas] eles pensam que é menos uma. Graças a Deus foi pro inferno aquela infeliz. É o que ela fala, a sociedade. (Entrevista realizada com Violeta, em Setembro de 2013, em Curitiba, no XX ENTLAIDS.)

\section{CONCLUSÕES}

A pesquisa realizada analisou como os espaços de morte são representados pelas travestis e transexuais femininas. A linearidade entre sexo, gênero, desejo e prática sexual estrutura a heterossexualidade compulsória na sociedade ocidental, conforme argumenta Butler (2003). Os corpos que fogem a esta norma sofrem diversas interdições ao longo de suas vidas por meio do espaço, como argumenta Valentine (1993). Silva (2009) e Namaste (2000) afirmam em suas pesquisas que travestis e transexuais femininas constituem o grupo de maior vulnerabilidade à violência da população LGBT. As autoras justificam este protagonismo pelo fato de que as travestis e transexuais possuem uma transgressão nítida, marcada no corpo, diferente de gays e lésbicas que podem tentar disfarçar sua orientação sexual por meio de estratégias de 'se passar por heterossexual' a fim de não sofrer violência.

A presença constante da vulnerabilidade à morte constitui um estilo de vida que dificulta a construção de estratégias para o enfrentamento da velhice, bem como de projetar a vida a longo prazo. As representações espaciais que elas constituem é de que o mesmo espaço da prostituição que lhe possibilita o sustento, e portanto a vida, é também aquele espaço de maior vulnerabilidade à violência e 
morte. Esta simultaneidade de significados opostos 'vida e morte' que se fazem a partir das experiências do espaço da prostituição não é uma escolha livre, mas uma politica espacial deliberada que as impede de constituir outras possibilidades de existência.

\section{REFERÊNCIAS}

ARIÉS, Pilippe. Sobre a história da morte no ocidente desde a idade média. Lisboa: Teorema, 1975

BARDIN, Laurence. Análise de Conteúdo. Lisboa: Edições 70, 1977.

BENEDETTI, Marcos Renato. Toda Feita: o corpo e o gênero das travestis. Rio de Janeiro: Garamond, 2005.

BUTLER, Judith. Problemas de Gênero: feminismo e subversão da identidade. Rio de Janeiro: Civilização Brasileira, 2003.

BUTLER, Judith. Deshacer el género. Barcelona: Paidós, 2006a.

BUTLER, Judith. Vida precaria. El poder y la violencia. Buenos Aires: Paidós, 2006b.

DOAN, Petra L. The tyranny of gendered spaces - reflections from beyond the gender dichotomy Gender, Place and Culture 17 n. 5, p. 635-654, 2010.

CABRAL, Vinicius; SILVA, Joseli Maria; ORNAT, Marcio Jose. "Espaço e morte nas representações sociais de travestis". In: SILVA, Joseli Maria;ORNAT, Marcio Jose.

CHIMIN JUNIOR, Alides Baptista (Orgs.). Geografias Malditas: corpos, sexualidades e espaço. Ponta Grossa: Toda Palavra, 2013. p.69-81.

DUNCAN, James S. The eity as text: the politics of landscape interpretation in the Kandyan kingdom. Cambridge: Cambridge University Press, 1990.

LOURO, Guacira Lopes. Um Corpo Estranho. Ensaios sobre sexualidade e teoria queer. Belo horizonte: Autêntica, 2008.

MOSCOVICI, Serge. Representações sociais: investigações em psicologia social. Petrópolis: Vozes, 2003.

MOTT, Luiz; CERQUEIRA, Marcelo. Matei porque odeio gay. Salvador: Editora Grupo Gay da Bahia, 2003.

NAMASTE, Viviane K. "Genderbashing: sexuality, gender and the regulation of public space". In: Namaste, Viviane K. Invisible Lives: The Erasure of Transsexual and Transgendered people. Chicago: University of Chicago Press, 2000. p.135156.

ORNAT, Marcio Jose. Território da Prostituição e a instituição do ser travesti em Ponta Grossa - PR. Dissertação de Mestrado (Mestrado em Gestão do Território). Universidade Estadual de Ponta Grossa, 2008.

ORNAT, Marcio Jose. “A instituição do território paradoxal na atividade da prostituição travesti”. In: SILVA, Joseli Maria, ORNAT, Marcio Jose e CHIMIN JUNIOR, Alides Baptista. (Orgs.). Geografias Malditas: corpos sexualidades e espaços. Ponta Grossa: Editora Toda Palavra, 2013, p.183-206.

ROSE, Gillian. Feminism \& geography: the limits of geographical knowledge. Cambridge: Polity Press, 1993. 
PELÚCIO, Larissa. Na Noite nem Todos os Gatos são Pardos. Notas sobre a prostituição travesti. cadernos pagu v.25, 2005, p.217-248.

SÁ, Celso Pereira. A Construção do Objeto de Pesquisa em Representações Sociais. Rio de Janeiro: EdUERJ, 1998.

SILVA, Joseli Maria; ORNAT, Marcio. "Dos Espaços Interditos à Instituição dos Territórios Travestis: Uma Contribuição às Geografias Feministas e Queer”. Terra Livre, v.2, p. 53-68, 2010.

SILVA, Joseli Maria. "A Cidade dos Corpos Transgressores da Heteronormatividade”. In: Silva, SILVA, Joseli Maria (Org.). Geografias Subversivas: discursos sobre espaço, gênero e sexualidade. Ponta Grossa: Editora Toda Palavra, 2009. p.136-149.

SILVA, Joseli Maria. "Espaço interdito e a experiência urbana travesti”. In: SILVA, Joseli Maria, ORNAT, Marcio Jose e CHIMIN JUNIOR, Alides Baptista. (Orgs.). Geografias Malditas: corpos sexualidades e espaços. Ponta Grossa: Editora Toda Palavra, 2013, p.85-142.

STRYKER, Susan. (De)Subjugated Knowledges: An introduction to transgender studies. In: STRYKER, Susan; WHITTLE, Stephen (Orgs.) The transgender studies reader. London: Routedge, 2006, p.1-17.

VALENTINE, Gill. (Hetero)sexing space: lesbian perceptions and experiences of everyday space. Environment and Planning D: Society and Space, v.11, n.4, p.395-413, 1993. 